\title{
Airsoft: an efficient and motivating cardiovascular training choice
}

José F. TORNERO-AGUILERA, Joaquin SANCHEZ-MOLINA, Vicente J. CLEMENTE-SUÁREZ

Abstract

BACKGROUND: Obesity and sedentarism have reached pandemic levels, postulating World Health Organization physical exercise as an important key factor for the prevention and treatment. In order to find a motivating and effective physical activity, we conducted this research intending to analyze the physiological and mechanical demands of an airsoft game. METHODS: Cardiovascular and mechanical activity were analyzed by heart rate monitors and GPS in 32 sedentary subjects ( $27.3 \pm 6.2$ years; $26.3 \pm 7.9$ BMI). RESULTS:

Participants performed moderate to vigorous aerobic intensity for 3 hours and 20 min of which $55.2 \%$ was between $60-70 \%$ of their maximal heart rate and $14.2 \%$ above $70 \%$ of it, turned into distance $9.5 \mathrm{~km}$ of which $91.5 \%$ was moderate and $8.5 \%$ vigorous intensity. CONCLUSIONS: A single airsoft game performed by sedentary subject exceed the international recommendation of physical activity and weekly physical activity of US adults' citizens. This motivating and outdoor activity is an effective alternative to increase the population's physical activity levels.

Keywords: Exercise; Obesity; Heart rate; Exercise 